\title{
The Investigation of Knitted Materials Bonded Seams Behaviour upon Cyclical Fatigue Loading
}

\author{
Gita BUSILIENE ${ }^{1 *}$, Eugenija STRAZDIENE ${ }^{2}$, Virginijus URBELIS ${ }^{3}$, \\ Sigitas KRAULEDAS ${ }^{4}$
}

\author{
${ }^{1}$ Faculty of Mechanical Engineering and Design of Kaunas University of Tecchnology, Studentu str. 56, Kaunas LT51424, \\ Lithuania \\ ${ }^{2}$ Vilnius University of Applied Sciences, Didlaukio str. 82, Vilnius LT-08303, Lithuania \\ ${ }^{3}$ Product Development Department, Granberg AS, Bjoavegen 1442, 5584 Bjoa, Norway \\ ${ }^{4}$ Textile Institute of Center for Physical Sciences and Technology, Demokratu str. 53, Kaunas LT-48485, Lithuania
}

crossref $\mathrm{http}: / / \mathrm{dx}$.doi.org/10.5755/j01.ms.23.2.16065

Received 18 August 2016; accepted 17 October 2016

\begin{abstract}
In this research uniaxial tension behaviour of knitted materials with bonded seams is analysed. The objects of the investigation were two types of knitted materials, having the same fibre composition (93\% PES, $7 \%$ EL), but different in knitting pattern, i. e. plain single jersey and $1 \times 1 \mathrm{rib}$. Bonded overlap seams were formed by changing the orientation of knitted materials strips, i. e. parallel/parallel, parallel/bias, parallel/perpendicular, bias/bias and bias/perpendicular. The strips of each knitted material were joined by two types of thermoplastic polyurethane (PU) films different in thickness $(75 \mu \mathrm{m}$ and $150 \mu \mathrm{m})$. Mechanical characteristics of bonded seams were defined in longitudinal tension direction direction. During uniaxial tension such parameters as maximal force $F_{\max }(\mathrm{N})$ and maximal elongation $\varepsilon_{\max }(\%)$ were recorded from typical tension diagrams. The changes of tested specimens' strength and deformation were compared before and after cyclical fatigue tension the conditions of which were 50 cycles up to tension force $F$ equal $24.5 \mathrm{~N}$. The results have shown that changes before and after cyclical fatigue tension are mostly determined by knitting pattern of materials, the orientation of knitted materials strips in bonded seam, but not effected by thermoplastic polyurethane film.
\end{abstract}

Keywords: knitted, bonded seam, uniaxial tension, fatigue loading, thermoplastic film.

\section{INTRODUCTION}

In recent seam bonding is replacing traditional sewing methods in sailings, bag filters, inflatable boats, inflatable toys, etc. The customers are looking for seamless products among outdoor, sportswear and functional garments, air bags, automotive and household products. Seam bonding and welding are two basic methods for joining textiles materials. In the first method thermoplastic film is applied for bonding two layers of textile. It is activated by heat and pressure, i.e. film melts and penetrates into the material by creating joint between two layers. The second method involves welding of two fabrics by using hot air, hot wedge, ultrasonic energy, laser, radio frequency or impact [1-3]. Bonded seams are characterized by smooth surface, seamless appearance and enhanced wearer comfort. They have good permeability, improved strength and recovery properties and make products lighter, stronger, more flexible and stretchable compared to sewn garments [1,3,4]. Different thermoplastic films can be used to bond the same or different materials [4-9]. On the other hand, materials or fabric pieces can be bonded with accessories comprising membranes, linings, buttons, zippers, tapes and waddings [1, 4, 10, 11].

Bemis company is producing thermoplastic adhesive films which are used to replace stitched seams by bonded

\footnotetext{
${ }^{*}$ Corresponding author. Tel.: +370-620-88113.

E-mail address: gita.busiliene@gmail.com (G. Busilienè)
}

joints. They are made from five polymer types such as polyurethane, nylon (polyamide), polyester, polyolefin and vinyl $[4,5]$. Sewfree is a soft, highly elastic, specially formulated polyurethane adhesive film designed for fabrics and has been proven in the applications ranging from intimate apparel, life style garments, industrial work wear, tents, waders, military garments, accessory items such as zips, pockets, cuffs, hems and patches $[4,5]$. The investigations of woven, knitted and laminated textile materials bonded seams strength have shown that the quality of bonds depend upon proper selection of parameters at two bonding stages: film transfer and layer bonding. The strength of bonded seams was investigated on base delamination and shear, the samples with bonded seams were fixed in testing machine grips by cross direction $[12,13]$. Innovative materials joining methods enter fashion industry. They allow to construct garments of exceptional design and performance properties. The area of bonded seams is not sufficiently studded yet, especially when separate pieces of knitted materials are bonded in different directions - course, wale or bias. The quality of such seams is dependent upon the structure of jointed materials, their mechanical properties, orientation and the type of bonding materials. On the other hand, the quality of seams defines aesthetic view of garments, their physiological comfort and durability, e.g. of close fitted sports clothing.

Our previous investigation has shown that the behaviour of knitted materials bonded seams under biaxial 
punching before and after cyclical fatigue punching are mostly determined by the thickness of thermoplastic film, but not effected by the orientation of knitted materials strips in bonded seams [14]. The aim of this investigation was to determine the effect of thermoplastic film and the orientation of knitted materials strips in bonded seams upon deformational behaviour of knitted materials bonded seams under uniaxial tension before and after cyclical fatigue loading.

\section{EXPERIMENTAL DETAILS}

Two types of knitted materials of the same fibre content (93\% PES, $7 \%$ EL), which were produced at Lithuania State Research Institute Centre for Physical Sciences and Technology were investigated. The first material $P$ of plain jersey knitting pattern was knitted on single jersey circular knitting machine "JEPY" 18E. The second material $R$ of $1 \times 1$ rib pattern was knitted on a double jersey circular knitting machine "CMO4A" $15 \mathrm{E}$. Both samples were produced using the same polyester fibre spun yarn the density of which was 20 tex and the same elastane yarn the density of which was 4.4 tex (Table 1). The stitch density $S$ was determined by calculating the number of courses and wales per unit length according to EN ISO 14971:2006 standard. The area density $m$ was determined according to EN ISO 12127:1999 and the thickness $t$ was determined according to EN ISO 5084:2000 standard.

Two thermoplastic polyurethane $(P U)$ films having different nominal thickness $t_{n}$ and modulus $m_{d}$, were used for the investigations (Table 2). The types of films were selected taking into account the recommendations of Bemis company, which stated that both Sewfree ${ }^{\circledR}$ brand thermoplastic films can adhere to a wide range of textile materials. Soft elastomeric adhesives are designed to be used in the applications where heat sensitive fabrics, low activation temperatures and high elasticity is required. Product B1 (3415) is described as "good" and product B2 $(3206 D)$ is described as "excellent" in the applications with polyester fabrics $[4,5]$. The specimens $(200 \times 50 \mathrm{~mm})$ were prepared with bonded overlap seams the width of which was $10 \mathrm{~mm}$ and which were oriented in longitudinal tension direction of the specimen (Fig. 1). Five types of bonded samples for each knitted material and thermoplastic film were constructed by changing the orientation of knitted material strips $(200 \times 30 \mathrm{~mm})$ in respect to specimen's longitudinal direction (Fig. 1): $W W-$ both material strips were tensioned in wale direction; $W C-$ one material strip was tensioned in wale, the other in course direction; W45 - one material strip was tensioned in wale, the other in bias $\left(45^{\circ}\right)$ direction; $C C$ - both material strips were tensioned in course direction; $C 45$ - one material strip was tensioned in course, the other in bias $\left(45^{\circ}\right)$ direction.

The specimens bonding was performed with $G T K$ $D E A 25 R$ press at two stages using the same $0.3 \mathrm{~N} / \mathrm{mm}^{2}$ (3 Bar) pressure: $1^{\text {st }}$ - thermoplastic film of $10 \mathrm{~mm}$ width was transferred onto the right side of lower strip by applying $110^{\circ} \mathrm{C}$ temperature for $5 \mathrm{~s}$; silicon paper was peeled off in 5 minutes; $2^{\text {nd }}$ - the left side of upper strip was laid on the thermoplastic film and was bonded by applying $140{ }^{\circ} \mathrm{C}$ temperature for $30 \mathrm{~s}$.

Table 1. Characteristics of investigated knitted materials

\begin{tabular}{|c|c|c|c|c|c|c|}
\hline \multirow{2}{*}{$\begin{array}{l}\text { Fabric } \\
\text { symbol }\end{array}$} & \multirow{2}{*}{ Fabric content } & \multirow{2}{*}{$\begin{array}{l}\text { Knitting } \\
\text { pattern }\end{array}$} & \multicolumn{2}{|c|}{ Stitch density $S, \mathrm{~cm}^{-1}$} & \multirow{2}{*}{$\begin{array}{l}\text { Area density } m, \\
\mathrm{~g} / \mathrm{m}^{2}\end{array}$} & \multirow{2}{*}{$\begin{array}{c}\text { Thickness } \\
t, \mathrm{~mm}\end{array}$} \\
\hline & & & courses, $S_{\mathrm{v}}$ & wales, $S_{\mathrm{h}}$ & & \\
\hline $\mathrm{P}$ & \multirow{2}{*}{$93 \%$ PES, $7 \%$ EL } & plain jersey & 28.0 & 16.0 & 284 & 1.16 \\
\hline $\mathrm{R}$ & & $1 \times 1 \mathrm{rib}$ & 23.0 & 25.0 & 340 & 1.32 \\
\hline
\end{tabular}

Table 2. Characteristics of investigated thermoplastic polyurethane (PU) films [4]

\begin{tabular}{|c|c|c|c|c|c|c|}
\hline Symbol & Code* & $\begin{array}{c}\text { Glue line temperature } \\
\text { range }\end{array}$ & Softening point & $\begin{array}{c}\text { Nominal thickness } \\
t_{n}, \mu \mathrm{m}\end{array}$ & $\begin{array}{c}\text { Weight } m, \mathrm{~g} / \mathrm{m}^{2} \\
\text { Modulus } \\
\mathrm{N}{ }^{* *} m_{d},\end{array}$ \\
\hline B1 & 3415 & $130{ }^{\circ} \mathrm{C}-140{ }^{\circ} \mathrm{C}$ & $75{ }^{\circ} \mathrm{C}$ & 75 & 93 & 6.7 \\
\hline B2 & $3206 \mathrm{D}$ & $83 \mathrm{C}$ & 150 & 186 & 17.8 \\
\hline
\end{tabular}

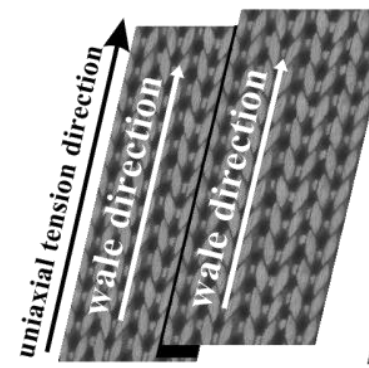

1. WW

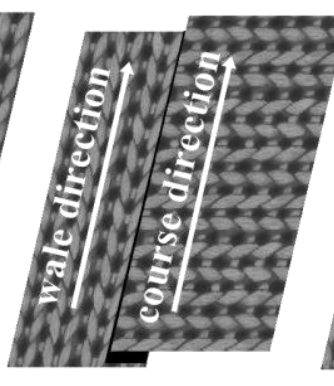

2. WC

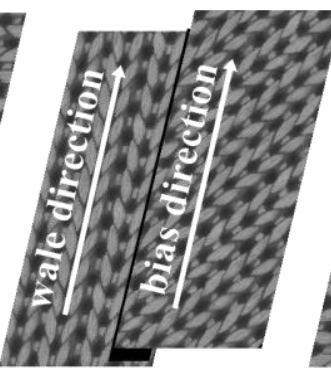

3. W45

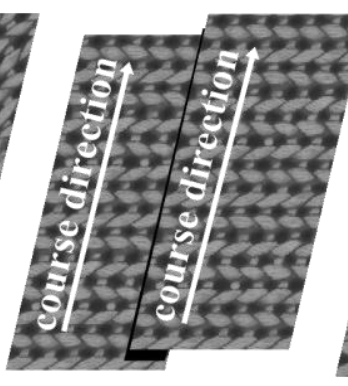

4. CC

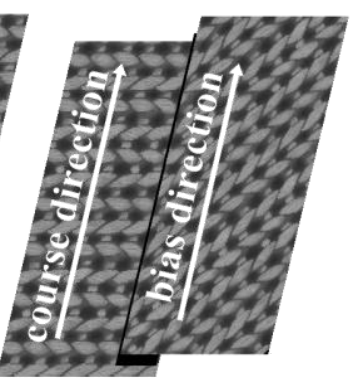

5. C45

Fig. 1. The schemes of knitted material strips orientation in bonded overlap seams 


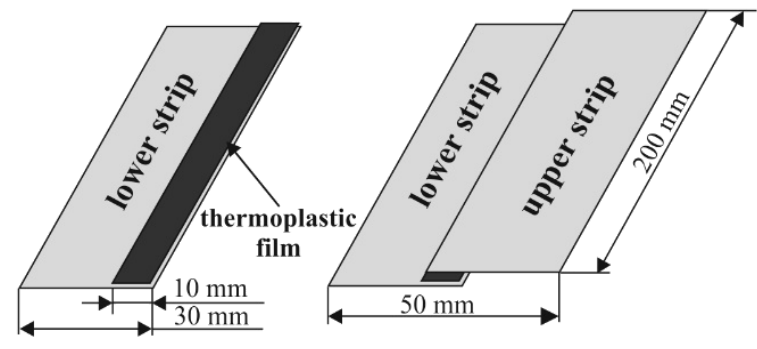

Fig. 2. The scheme of knitted materials strips bonding with thermoplastic polyurethane (PU) films

Bonding conditions were chosen not only taking into account the recommendations of Bemis company, but also in respect to the results of earlier investigations $[4,5,12,13]$. All specimens before testing were kept in standard atmosphere conditions $(\varphi=65 \pm 2 \%$, $T=20 \pm 2^{\circ} \mathrm{C}$ ) for 24 hours according to standard EN ISO 139:2005.

Strength parameters, deformation behaviour and anisotropy level of bonded systems were defined and evaluated by uniaxial tensile testing (Fig. 3). Uniaxial tension before and after samples fatigue loading by 50 cycles was performed with standard tensile testing machine Tinius Olsen $\mathrm{H} 10 \mathrm{~K}$ according to the requirements to EN ISO 13934-1 standard. Testing conditions were: specimen length between testing machine grips $-100 \mathrm{~mm}$, specimen width $-50 \mathrm{~mm}$, pre-tension $-1 \mathrm{~N} / 5 \mathrm{~cm}$, tension rate $100 \mathrm{~mm} / \mathrm{min}$. Maximal force $F_{\max }(\mathrm{N})$ and maximal elongation $\varepsilon_{\max }(\%)$ were recorded from typical tension curves. The number of specimens for one sample was 5 , variation coefficient did not exceed $8 \%$. The conditions of cyclical tensile fatigue loading were -50 cycles up to tension force $F=24.5 \mathrm{~N}$, which correspond to garments wearing load [15]. The velocity of cyclical tensile fatigue loading was $500 \mathrm{~mm} / \mathrm{min}$. The number of specimens for one sample was 5 , the variation coefficient did not exceed $7.5 \%$.

\section{RESULTS AND DISCUSSION}

Two knitted materials which are different in knitting pattern, stitch density $S$, area density $m$ and thickness $t$ were chosen for the investigation of bonded seams behaviour in uniaxial tension. Stitch density of plain jersey knitted material $P$ is higher by $21.7 \%$ in wale direction and lower by $56.3 \%$ in course direction as compared to $1 \times 1$ rib knitted material $R$. Meantime $R$ material can be characterised by $19.7 \%$ higher area density $m$ and by $13.8 \%$ higher thickness $t$ when compared to plain single jersey knitted material $P$.

Typical uniaxial tension curves of non-bonded knitted materials $P$ and $R$ are presented in Figure 3. It is evident that there is no significant difference in tensile behaviour of plain jersey knitted material $P$ in wale and course directions (Fig. 3, a). The behaviour of $1 \times 1$ rib knitted material $R$ in wale and course directions differs significantly (Fig. 3, b). Also, $P$ sample can be characterised as less anisotropic because its maximal force $F_{\max }$ and maximal elongation $\varepsilon_{\max }$ in wale and course directions differ by $15.8 \%$ and $10.1 \%$, respectively (Table 3 ). Higher anisotropy is characteristic for knitted material $R$, because maximal force in wale direction is higher almost twice (95\%) and elongation in this direction is less more than twice $(112.8 \%)$ when compared to course direction (Table 3) [16].

Five types of bonded seams were prepared with both investigated materials $P$ and $R$ and both thermoplastic films $B 1$ and $B 2$ according to the schemes, which are presented in Figure 1. Uniaxial tension curves of two main seam types: $W W$ (both bonded strips were tensioned in wale direction) and $C C$ (both bonded strips were tensioned in course direction) are presented in Figure 3. The results show that no significant difference exists if seams were bonded with $B 1$ or $B 2$ polyurethane films, because $F_{\max }$ and $\varepsilon_{\max }$ values did not exceed error limits. It was observed that the strength $F_{\max }$ of bonded seams $P B 1 W W, P B 2 W W$, $P B 1 C C, P B 2 C C$ of less anisotropic material $P$ decreased by $18 \%$ and by $25 \%$ in respect to non-bonded material strengths in wale and course directions. Maximal elongation $\varepsilon_{\max }$ of the same seams decreased by $66 \%$ and $77 \%$, respectively (Fig. 3, a). Different results were obtained for more anisotropic $R$ materials bonded seams $R B 1 W W, R B 2 W W, R B 1 C C$ and $R B 2 C C$, which were stronger by $102 \%$ and by $52 \%$ in respect to non-bonded material strengths in wale and course directions (Fig. 3, b), though extensibility became less by $117 \%$ and $86 \%$, respectively. The assumption can be made that bonded systems $W W$ and $C C$ from less anisotropic material became weaker and less extensible, but almost twice stronger, especially when tensioned in wale direction, and less extensible for more anisotropic material in comparison to non-bonded samples.

There is no evident difference between the maximal elongation $\varepsilon_{\max }$ of all ten types of bonded seams of knitted material $P$ - the same as there is no significant difference between the elongations $\varepsilon_{\max }$ in wale $P_{\mathrm{w}}$ and course $P_{\mathrm{c}}$ directions of non-bonded samples (Fig. 4, a). It should be noted that bonded seams are less extensible by $59.6 \% \div$ $82.1 \%$ and by $75.7 \% \div 100.5 \%$ when compared to elongations in wale $P_{\mathrm{w}}$ and course $P_{\mathrm{c}}$ directions.

Deformational behaviour of ten types of anisotropic $R$ materials bonded seams is different.

Table 3. Uniaxial tension characteristics of knitted materials

\begin{tabular}{|c|c|c|c|c|c|c|}
\hline \multirow{2}{*}{$\begin{array}{c}\text { Material } \\
\text { symbol }\end{array}$} & \multicolumn{2}{|c|}{ Wale direction } & \multicolumn{2}{c|}{ Course direction } & \multicolumn{2}{c|}{ Anisotropy coefficient at maximal } \\
\cline { 2 - 7 } & $F_{\text {maxw }}, \mathrm{N}$ & $\varepsilon_{\operatorname{maxw}}, \%$ & $F_{\operatorname{maxc}}, \mathrm{N}$ & $\varepsilon_{\operatorname{maxc}}, \%$ & force, $K_{\mathrm{F}}=F_{\operatorname{maxc}} / F_{\operatorname{maxw}}$ & elongation, $K_{\varepsilon}=\varepsilon_{\operatorname{maxw}} / \varepsilon_{\operatorname{maxc}}$ \\
\hline $\mathrm{P}$ & 296.7 & 545.3 & 256.3 & 600.2 & 0.86 & 0.91 \\
\hline $\mathrm{R}$ & 264.8 & 324.0 & 134.7 & 693.0 & 0.51 & 0.47 \\
\hline
\end{tabular}




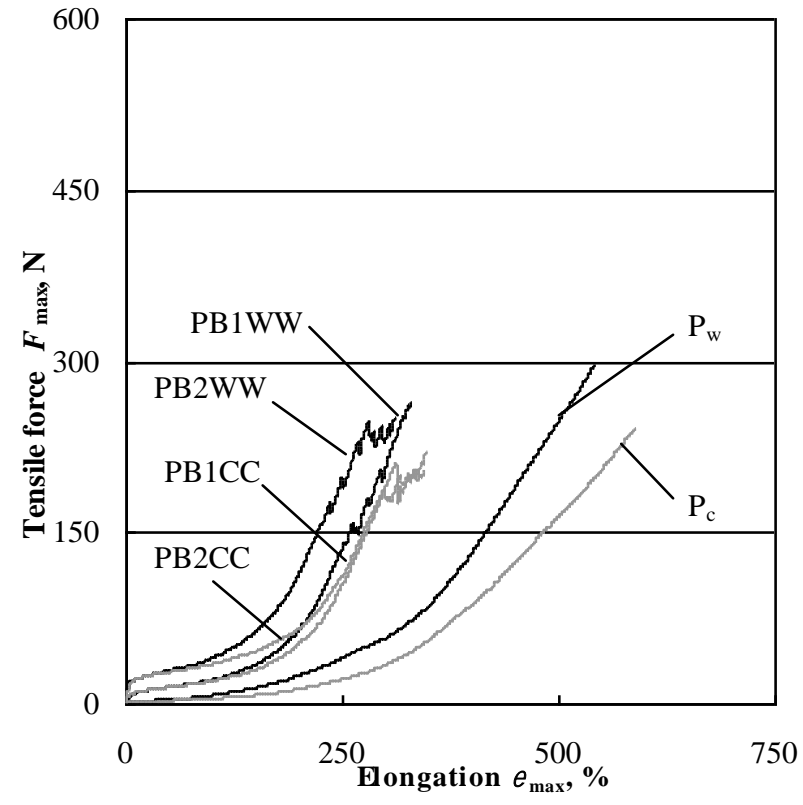

a

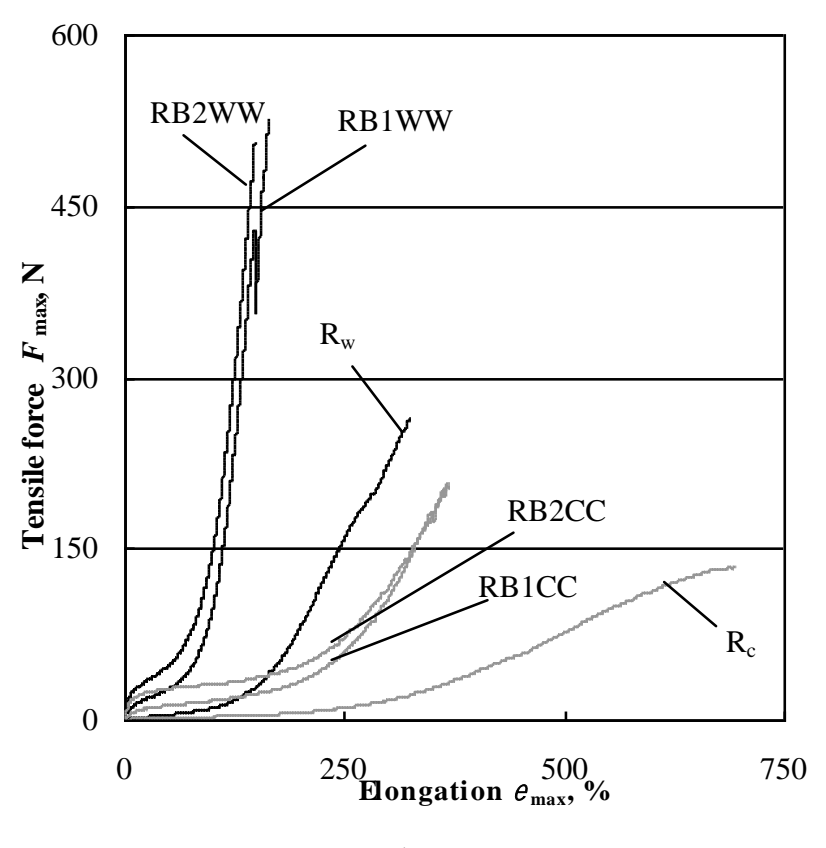

b

Fig. 3. Typical uniaxial tension curves of investigated materials $P$ (a) and $R$ (b) and their bonded systems $W W$ and $C C$, where $c-$ course direction; $w$ - wale direction (coefficient of variation varied in the limits of $2.16 \% \div 5.78 \%$ )

The lowest elongations were obtained for: $W W$ seam where both material strips were tensioned in wale direction; WC seam, where one material strip was tensioned in wale, the other in course direction; W45 seam, where one material strip was tensioned in wale, the other in bias $\left(45^{\circ}\right)$ direction (Fig. $4, \mathrm{~b}$ ). The highest elongation (higher by $150 \%$ in respect to $W W$ seam) was characteristic for $C C$ seam, where both material strips were tensioned in course direction. Medium elongation (higher by $59 \%$ in respect to $W W$ seam) was characteristic for $C 45$ seam, where one material strip was tensioned in course, the other in bias $\left(45^{\circ}\right)$ direction. It is evident that bonded seams one strip of which is tensioned in wale direction, e.g. $W W, W C, W 45$, will be characterised by the lowest elongation values, even lower than those of non-bonded $R$ materials: from $82.5 \%$ to $125.2 \%$ in respect to wale $R_{\mathrm{w}}$ and from $288.4 \%$ to $379.4 \%$ in respect to course $R_{\mathrm{c}}$ direction. It should be noted that extensibility of $C C$

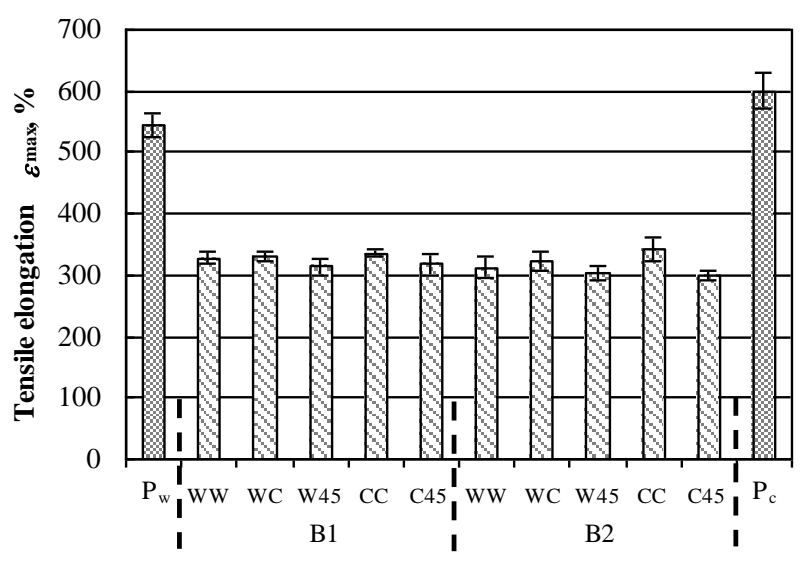

a bonded seam are similar to the extensibility of non-bonded material in wale $R_{\mathrm{w}}$ direction. Meantime the most significant effect upon bonded seams strength and extensibility was obtained taking into account the type of knitting pattern and the orientation of materials strips in bonded seams, especially in the case of $1 \times 1$ rib knitted $R$ material.

The results of cyclical tensile fatigue loading by 50 cycles up to tension force $F=24.5 \mathrm{~N}$ show that it has no significant effect upon tensile elongation of bonded systems with both $B 1$ and $B 2$ thermoplastic films (Fig. 5 ,a). The elongation $\varepsilon_{\max 50}$ of bonded seams from plain jersey knitted material $P$ decreased by $8.8 \%$, the elongation $\varepsilon_{\max 50}$ of bonded seams from $1 \times 1$ rib knitted material $R$ increased by $12.7 \%$, except bonded seams $R B 1 W C$ and $R B 1 W 45$, they incresed by $9.8 \%$ (Fig. 5, b).

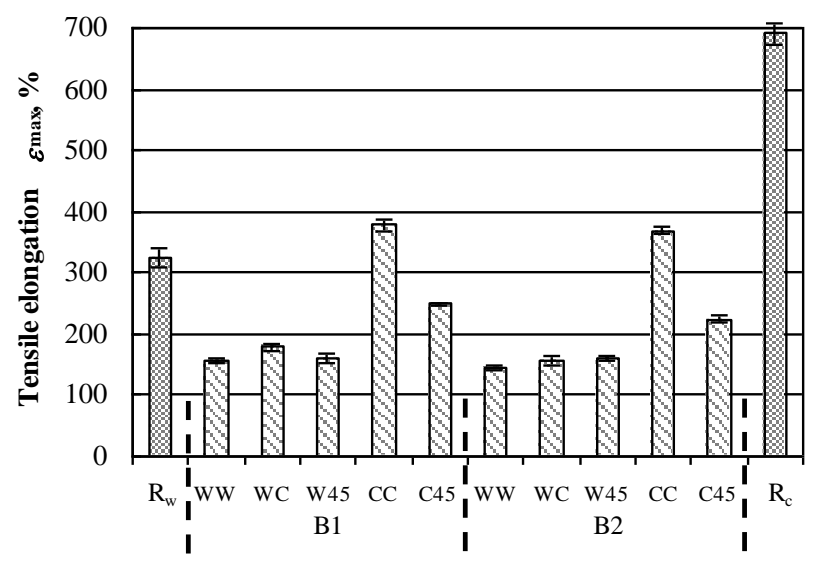

b

Fig. 4. Uniaxial elongation of plain jersey knitted material in wale $P_{\mathrm{w}}$ and course $P_{\mathrm{c}}$ directions (a), and of $1 \times 1$ rib knitted material in wale $R_{\mathrm{w}}$ and course $R_{\mathrm{c}}$ directions (b), and ten types of bonded seams (coefficient of variation varied in the limits of $0.61 \% \div 5.81 \%)$ 


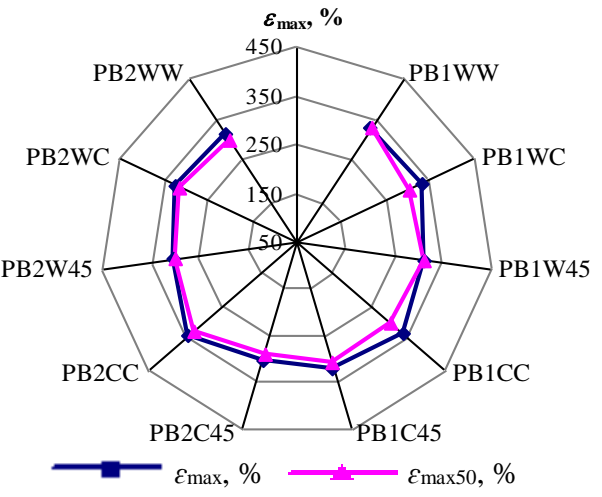

a

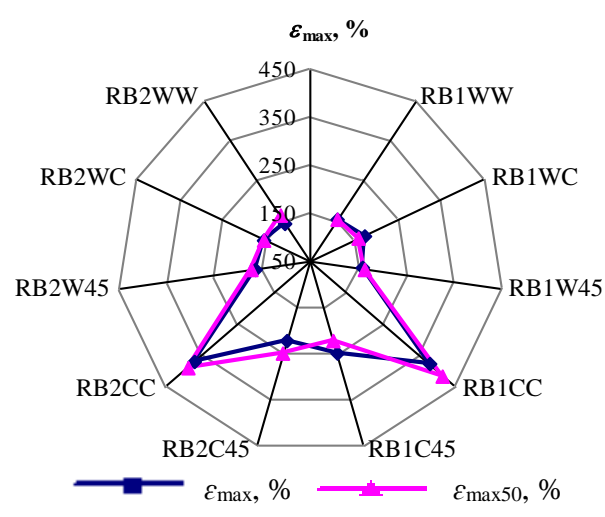

b

Fig. 5. Uniaxial elongation of plain jersey knitted $P$ materials (a) and $1 \times 1$ rib knitted $R$ materials (b) bonded seams before $\varepsilon$ max and after uniaxial fatigue loading $\varepsilon_{\max 50}$ (coefficient of variation varied in the limits of $0.61 \% \div 7.99 \%$ )

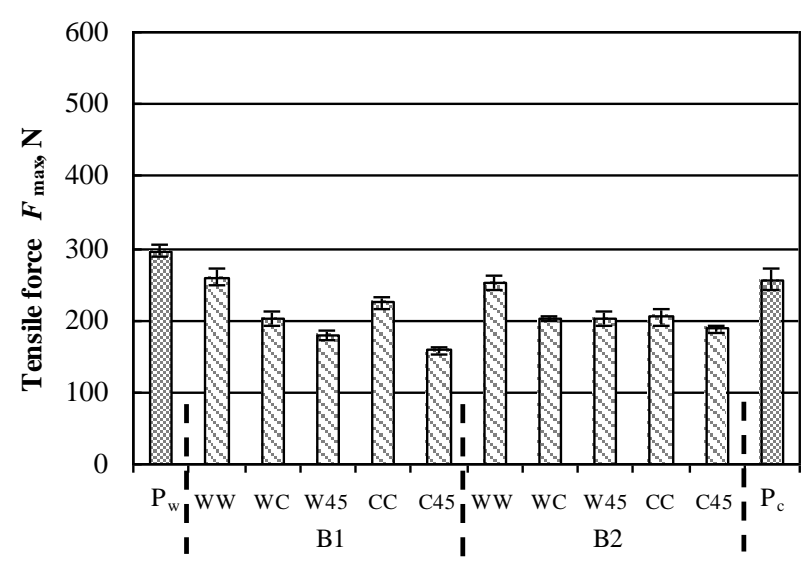

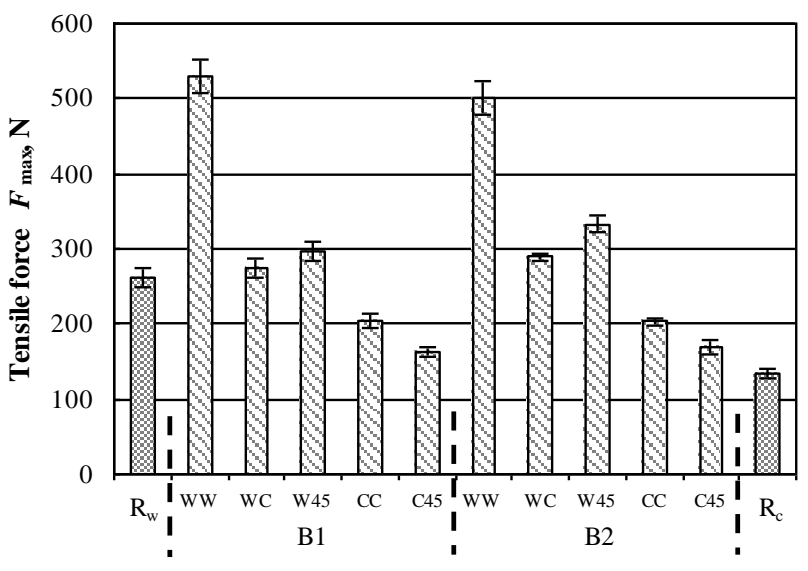

b

Fig. 6. Uniaxial tensile force of plain jersey knitted and material in wale $P_{\mathrm{w}}$ and course $P_{\mathrm{c}}$ directions (a) and of $1 \times 1$ rib knitted in wale $R_{\mathrm{w}}$ and course $R_{\mathrm{c}}$ directions (b), and ten types of bonded seams (coefficient of variation varied in the limits of $1.48 \% \div 5.78 \%$

Bonded seams $W W$ and $C C$ of plain jersey knitted material $P$ are the strongest, while bonded seam $C 45$ is the weakest (Fig. 6, a). The difference of $F_{\max }$ between them reaches $64.7 \%$ in the case of $B 1$ thermoplastic film. Maximal strength of the seams bonded with thermoplastic film $B 2$ are more stable, because the difference between them is only $32.2 \%$. It can be seen that the strength of seams where both strips are orientated in wale $W W$ direction is similar to the strength of non-bonded material

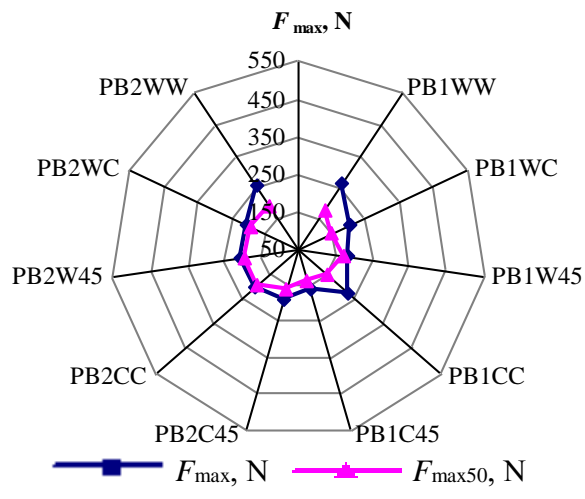

a in wale $P_{\mathrm{w}}$ and course $P_{\mathrm{c}}$ directions (Fig. 6, a). In the case of $1 \times 1$ rib knitted material $R$ the strongest are the seams where both bonded strips are orientated in wale $W W$ direction, the weakest $-C C$ and $C 45$ seams. In Figure $6, \mathrm{~b}$ it can be seen that the strength of WC and W45 seams is close to the strength of non-bonded material in wale $R_{\mathrm{w}}$ direction. The difference between them comprises $4.4 \% \div$ $26.7 \%$. The strength of $C 45$ seam is close to the strength of non-bonded material in course $R_{c}$ direction.

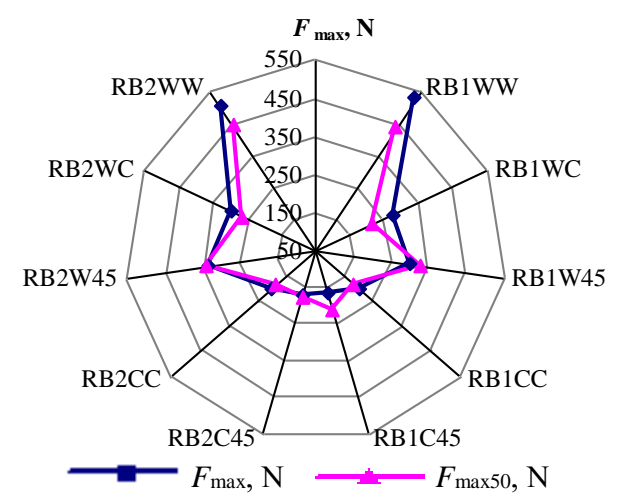

b

Fig. 7. Uniaxial tensile forces of plain jersey knitted material $P$ (a) and $1 \times 1$ rib knitted materials $R$ (b) bonded seams before $F_{\max }$ and after uniaxial fatigue loading $F_{\max 50}$ (coefficient of variation varied in the limits of $0.40 \% \div 7.50 \%$ ) 
The difference between them is $21.9 \% \div 26.1 \%$. The results of cyclical tensile fatigue loading revealed that it had insignificant effect upon tensile strength $F_{\max 50}$ of knitted materials $R$ bonded seams (Fig. 7, b), but it effected the strength $F_{\max 50}$ of plain jersey knitted material $P$ bonded seams, especially when bonded with $B 1$ thermoplastic film (Fig. 7, a) the modulus of which is more than twice lower than that of $B 2$ film (Table 2). The highest decrease was observed for bonded seams $W W$ $(49.3 \%), W C(35.6 \%)$ and $C C(48.8 \%)$, which were bonded with $B I$ film and for bonded seam $W W(34.1 \%)$, which was bonded with $B 2$ film. A little bit lower decrease was observed for $C 45(15.5 \%)$ and $C 45(18.3 \%)$ bonded seams with both thermoplastic films $B 1$ and $B 2$. In the case of $1 \times 1$ rib knitted material $R$ medium decrease in the limits of $8.9 \% \div 25.8 \%$ was observed for $W W$ and $W C$ seams bonded with both $B 1$ and $B 2$ thermoplastic films.

\section{CONCLUSIONS}

The effect of thermoplastic film thickness and the orientation of knitted materials strips upon uniaxial tensile behaviour of bonded overlap seams before and after cyclical fatigue loading was determined. The strength and extensibility of bonded seams strongly depend upon the structure of knitted material ant its orientation in the seam. Investigation results have revealed that more stable seams are obtained for less anisotropic materials. The performance of such seams is close to that of non-bonded materials deformational behavior.

The results of the investigations have shown that the orientation of strips of low anisotropy material $P$ does not have significant effect upon deformational behaviour of bonded seams. The seams $W W$, where both strips are orientated in wale direction, are stronger by $64.7 \%$ when compared to the other seams, but weaker by $18 \%$ when compared to the strength of non-bonded material strength in wale $P_{\mathrm{w}}$ and course $P_{\mathrm{c}}$ directions.

It must be noted that the extensibility of all the seams made of $P$ material are similar, but less extensible by $59.6 \% \div 100.5 \%$ when compared to non-bonded knitted material $P$ tensioned in both directions. Different results were obtained in the case of high anisotropy material $R$, because the orientation of material strips had evident effect upon deformational behaviour of bonded seams. The seams $W W$, both strips in which are orientated in wale direction, became stronger by $223.3 \%$ when compared to the other seams and stronger by $294.3 \%$ when compared to non-bonded knitted material strength tensioned in wale $P_{\mathrm{w}}$ and course $P_{\mathrm{c}}$ directions. The weakest are $C 45$ seams the strength of which are close to non-bonded knitted material in course direction $R_{\mathrm{c}}$, but weaker by $26 \%$ in respect to non-bonded knitted materials strength in wale direction $R_{\mathrm{w}}$. The strength of WC and W45 seams are close to non-bonded knitted materials strength in wale direction $R_{\mathrm{w}}$. The most extensible are $C C$ bonded seams the extensibility of which are close to non-bonded knitted materials extensibility in wale direction $R_{\mathrm{w}}$, but lower by $87.1 \%$ in respect to non-bonded knitted materials extensibility in course direction $R_{\mathrm{c}}$. The lowest extensibility is characteristic for $W W, W C$ and $W 45$ seams and it is less by $112.3 \% \div 156.2 \%$ when compared to the extensibility of $C C$ seams and by $82.5 \% \div 112 \%$, and by $288.4 \% \div 379.4 \%$ in respect to non-bonded knitted materials extensibility in wale $R_{\mathrm{w}}$ and course $R_{\mathrm{c}}$ directions, respectively.

\section{REFERENCES}

1. Jana, P. Assembling technologies for functional garments - An overview. Indian Journal of Fibre and Textile Research 36 2011: pp. $380-387$.

2. Gierenz, G., Karmann, W. Adhesive and Adhesive Tapes, Wiley-VCH Verlag gmbh, 2001: 138 p.

3. Jones, I.-A., Wise, R.-J. Novel joining methods applicable to textiles and smart garments. Paper presented at Wearable Futures Conference, University of Wales, Newport, Wales, 14-16 September 2005. (accessed 18 July 2014).

4. Bemis Associate Inc. Bemis Selector Guide Thermoplastic Adhesives, Specialty Films and Seam Tape. 1029 Rev. N 03/2012. (accessed 05 November 2013)

http://www.bemisworldwide.com/selector-guide.php

5. Performance apparel Markets Business and market analysis of word wide trends in high performance active wear and corporate apparel, Textiles Intelligence Limited, 2006, 16, pp. 38-47 (accessed 05 November 2013).

http://www.gradozero.eu/gzenew/im/press/pdf_1/2006_1_1_perf ormance_apparel_markets_issue_16.pdf

6. Gorchakova, V.-M., Batalenkova, V.-A., Izmailov, B.-A. Autoadhesive bonding of motified polyester fibres Fibre Chemistry 35 (1) 2003: pp. 39-40.

7. Darwish, N.-A., El-Wakil, A.-A., Abou-Kandil, A.-I. Effect of bonding systems and antioxidants on the adhesion between EPDM rubber and polyester fabric International Journal of Adhesion and Adhesives 29 2009: pp. 745-749.

8. Bhat, G.-S., Jangala, P.-K., Spruiell, J.-E. Thermal bonding of polypropylene nonwovens: effect of bonding variables on the structure and properties of the fabrics Journal of Applied Polymer Science 92 2004: pp. 3593-3600.

9. Hedge, R.-R., Bhat, G.-S., Campbell, R.-A. Thermal bonding of polypropylene films and fibers Journal of Applied Polymer Science 110 2008: pp. 3047-3058.

10. Milašienè, D., Bubnytė, K. The influence of fatique conditions on the mechanical properties of laminated leather and its separate layers Materials Science (Medžiagotyra) 13 (3) 2007: pp. $210-213$.

11. Yang, C., Gao, P., Xu, B. Investigations of a controllable nanoscale coating on natural fifer system: effects of charge and bonding on the mechanical properties of textiles Journal of Materials Science 44 (2) 2009: pp. 469-476.

12. Jakubčionienė, Ž., Masteikaitè, V. Investigation of textile bonded seams Materials Science (Medžiagotyra) 16 (1) 2010: pp. $76-79$.

13. Jakubčionienè, Ž., $\quad$ Masteikaitè, V. Kleveckas, T., Jakubčionis, M., Kelesova, U. Investigation of the strength of textile bonded seams Materials Science (Medžiagotyra) 18 (2) 2012: pp. 172-176.

14. Busiliene, G., Strazdienè, E., Urbelis, V. The effect of bonded seams upon spatial behaviour of knitted materials systems Materials Science (Medžiagotyra) 21 (2) 2015: pp. 271-275.

15. Dapkūnienė, K., Strazdienė, E. Influence of layer orientation upon textile systems tensile properties. Part 2. Investigation of Tensile Energy and Linearity Materials Science (Medžiagotyra) 12 (3) 2006: pp. 247-252.

16. Semnani, D. Mechanical properties of weft knitted fabrics in fully stretched status along courses direction: geometrical model aspect Universal Journal of Mechanical Engineering 1 (2) 2013: pp. 62-67. 